\title{
Isla del Coco, on Cocos Plate, converges with Isla de San Andrés, on the Caribbean Plate, at $78 \mathrm{~mm} / \mathrm{yr}$
}

\author{
Marino Protti ${ }^{1}$, Víctor González ${ }^{1}$, Jeffrey Freymueller ${ }^{2} \&$ Sarah Doelger $^{3}$ \\ 1. Observatorio Vulcanológico y Sismológico de Costa Rica, Universidad Nacional, Apartado 1718-3000, Heredia, \\ Costa Rica; jprotti@una.ac.cr, vgonzale@una.ac.cr \\ 2. Geophysical Institute and Department of Geology and Geophysics, University of Alaska Fairbanks, 903 Koyukuk \\ Drive, Univ. of Alaska, Fairbanks, AK 99775-7320; jeff.freymueller -at- gi.alaska.edu \\ 3. UNAVCO, 3340 Mitchell Lane, Boulder, Colorado, 80301; doelger@unavco.org
}

Received 23-III-2012. C Corrected 22-VI-2012. Accepted 24-IX-2012.

\begin{abstract}
Isla del Coco is the only land mass of the Cocos Plate that emerges above sea level. This makes it the only place where Cocos Plate motion can be measured using Global Navigation Satellite System (GNSS) monitoring. Global Positioning System (GPS) observations have been carried out sporadically over more than two decades on Isla del Coco, allowing precise measurement of the motion of the Cocos Plate. Recently, in May 2011, a continuous GPS station was built and instrumented at Isla del Coco, in Wafer Bay, by OVSICORI-UNA and UNAVCO, as part of the COCONet regional GNSS network. Position time series from this CGPS station (ISCO: Isla del Coco) show a steady motion of Isla del Coco at a speed of $90.9 \pm 1.5 \mathrm{~mm} / \mathrm{yr}$ in the $\mathrm{N} 35^{\circ} \mathrm{E}$ direction in ITRF2008 and convergence with the Caribbean Plate at $78 \pm 1 \mathrm{~mm} / \mathrm{yr}$. This result is consistent with the findings of the earliest GPS studies, and agrees within uncertainty with the estimated convergence rate of $76.4 \pm \mathrm{X} \mathrm{mm} /$ $\mathrm{yr}$ of the MORVEL plate motion model. MORVEL is based on an average over the last 780,000 years, and our result suggests that Cocos-Caribbean plate motions have been constant over that time interval. Citation: Protti, M., V. González, J. Freymueller \& S. Doelger. 2012. Isla del Coco, on Cocos Plate, converges with San Andres Island, on the Caribbean Plate, at 78mm/yr. Rev. Biol. Trop. 60 (Suppl. 3): 33-41. Epub 2012 Dec 01.
\end{abstract}

Key words: Isla del Coco, Cocos Plate, Caribbean Plate, GPS, continuous GPS (CGPS), plate motion.

Measurements of positions using Global Navigation Satellite System (GNSS) technologies like the Global Positioning System (GPS) have been used to determine presentday tectonic plate velocities since the late 1980s (Freymueller et al., 1993, Dixon 1993). Initially, data was only collected in campaigns of observations during a few days per site, but now continuous recording receivers are being installed worldwide. At Isla del Coco, some $500 \mathrm{~km}$ SW from mainland Costa Rica, campaign style GPS observation have been carried out sporadically since 1988. In May 2011 a continuous recording GPS (CGPS) station was installed at Isla del Coco as part of both, the regional Continuous Caribbean Observation Network (COCONet), as well as the Nicoya
Geodynamic Monitoring System (SISMOGENICO, the Spanish acronym), a joint research project between OVSICORI-UNA and several US academic institutions.

We present here results from the GPS campaigns and preliminary results from almost one year of continuous recording at Isla del Coco. Taking advantage of another CGPS station running at Isla de San Andrés, on the stable Caribbean Plate (away from deformation associated with its plate boundaries), we also present the first continuous measurements of Cocos-Caribbean plate convergence.

Tectonic setting: Isla del Coco is an intraoceanic island that emerges from a submarine ridge. It is part of a series of young volcanoes 
on an old hot-spot trace (Castillo et al. 1988). This submarine ridge, the Cocos ridge, is one of the traces of the Galapagos hot spot; it was created by volcanism at the Galapagos Islands and is transported to the northeast toward Central America by Cocos Plate motion, where it subducts beneath the Osa Peninsula in southern Costa Rica (Fig. 1). This development history gives the ridge a $\mathrm{N} 40^{\circ} \mathrm{E}$ orientation, roughly normal to the trend of the Middle American Trench. The oceanic Cocos Plate is being created from both the fast-spreading East Pacific Rise (EPR), as well as from the slow Galapagos Spreading Center (GSC). The GSP originated when the Farallon plate broke out into Cocos and Nazca plate some 25 to 28 mya (Hey 1977, Lonsdale and Klitgord, 1978). Cocos is a fast moving plate with periods of superfast motion (around $200 \mathrm{~mm} / \mathrm{yr}$ of spreading at the EPR during the Mid-Miocene) (Wilson 1996).

The Cocos Plate subducts beneath the North American Plate in SE Mexico, under the Caribbean Plate in most of Central America, and beneath the Panama Block in SW Costa Rica. Convergence rates of the Cocos and Caribbean plates varies from about $65 \mathrm{~mm} / \mathrm{yr}$ in Guatemala to about $85 \mathrm{~mm} / \mathrm{yr}$ in Costa Rica (computed from DeMets 2001). The recent MORVEL plate motion model (DeMets et al. 2010), which is an average over the last 780,000 years rather than $\sim 3$ million years for DeMets (2001), predicts slower convergence rates about $10 \mathrm{~mm} / \mathrm{yr}$ slower, but a similar spatial variation.

\section{OBSERVATIONS}

Campaign measurements: A geodetic monument in Isla del Coco was first measured by GPS early in 1988 as part of the regional CASA UNO campaign. Two other campaigns were carried out in 1990 and 1991 as part of the CORBAS project and the monument was remeasured again then. GPS occupations were also done at Isla del Coco in 1994 and 2008. Unfortunately, the 1994 measurements were made at the wrong geodetic monument, and these data cannot be used to measure tectonic motions because the offset between these two monuments has never been measured precisely. The 1988-1991 data were used by Dixon (1993) and Freymueller et al. (1993) to make the first estimates of Cocos Plate motion relative to sites on Central America and in the

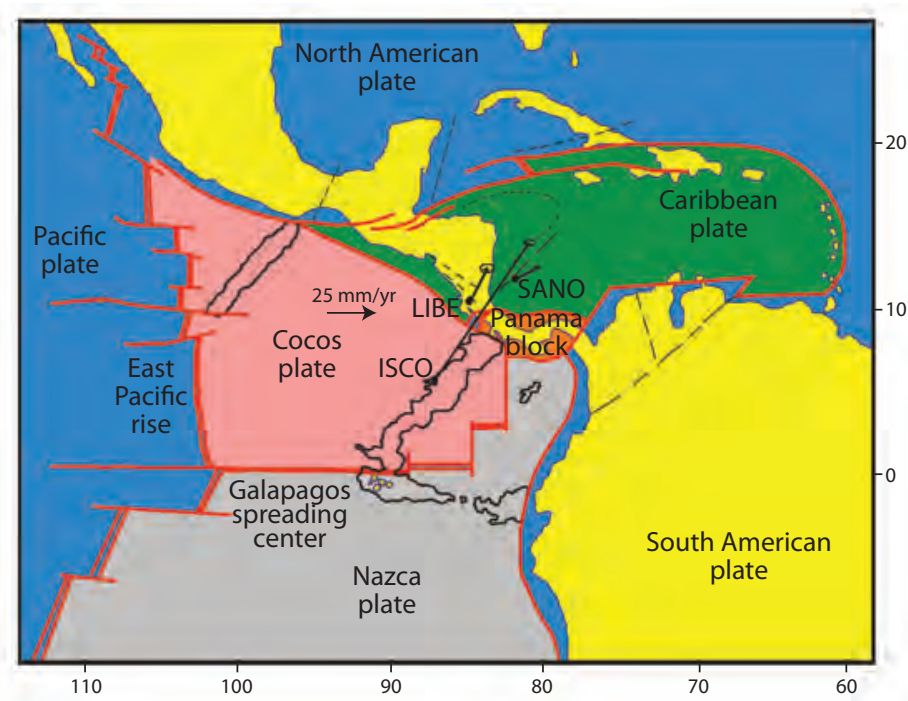

Fig. 1. Tectonic setting of Isla del Coco. Velocity vectors, in ITRF, with their error ellipses are shown for Isla del Coco (ISCO), Liberia (LIBE) and Isla de San Andrés (SANO). Scale vector is plotted above the Cocos plate label. 
Caribbean, which confirmed that the motions measured with GPS were generally consistent with the geologic global plate motion models. These early estimates however had large uncertainties in the motion rates, $4-7 \mathrm{~mm} /$ year. Data prior to 1991 are difficult to use today due to changes in data formats, lack of calibration of the equipment used then relative to the modern equipment we now use, and, most importantly, a lack of precise coordinates for the limited global tracking network that was in place at that time. While the results of these early studies generally agree with modern data at about the level expected given their uncertainties, post-1991 data are so much more precise because of the completion of the GPS satellite constellation and the development of a robust global tracking network that the early data do not contribute much information beyond what we obtain using 1991 and later data.

We present here results from the 1991 and 2008 campaigns. These occupations were done at a geodetic monument (Fig. 2) located at $\sim 140$ m.a.s.l. on a bare hill inland from the ranger station in Chatham Bay (Fig. 2). We also included data from 1991, 1994 and 1996 campaigns from the site Liberia on the Costa Rica mainland, to compare with and assess the quality of the velocities estimated for the 1988-1991 data (Dixon 1993, Freymueller et al. 1993).

Data processing was done at the Geophysical Institute, University of Alaska at Fairbanks. We use the GIPSY-OASIS software version goa-5.0, developed by the Jet Propulsion Laboratory (JPL). For all data prior to 1996, we estimate the satellite orbits using all of the available global sites operating at the time. For more recent data, we fix the satellite orbit and clock parameters to the current JPL satellite orbit and clock products. We process all stations one by one in a point positioning mode (Zumberge et al. 1997), and then combine all stations across a broad region to get a single set of coordinates each day. The daily coordinate solutions are then aligned with the International Terrestrial Reference Frame (ITRF2008) solution to resolve the origin, orientation and scale of the network. We then estimate station velocities by fitting a linear model to the station coordinates over time.

The Isla del Coco (ISCO) CGPS: A continuous GPS station was built and instrumented in May 2011 on Isla del Coco. This CGPS station is located at $5.5444^{\circ} \mathrm{N}$ and $87.0556^{\circ} \mathrm{W}$ on a sandy terrace at the Genio River delta in Wafer Bay, at $\sim 2$ m.a.s.l. The antenna monument is located right in the middle of this alluvial terrace, $40 \mathrm{~m}$ NW from the Villa Beatriz, the Park ranger station in Wafer Bay. The shoreline is $60 \mathrm{~m} \mathrm{NW}$ from the monument and there is a marsh in between.

The antenna is on a shallow drilled braced monument, built following the Plate Boundary Observatory standards (http://pbo.unavco.org/ instruments/gps) (Fig. 3). It has four legs, $4 \mathrm{~m}$
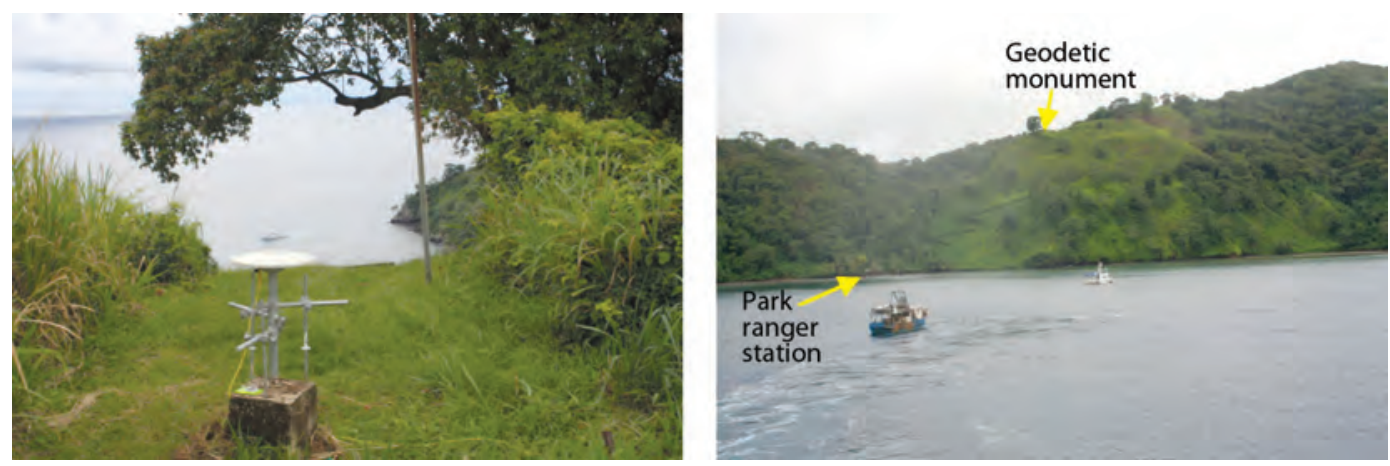

Fig. 2. Geodetic monument occupied at Chatham Bay in 1991 and 2008 (left). View from Chatham Bay showing location of geodetic monument of campaign site $\mathrm{COCO}$ (right). 

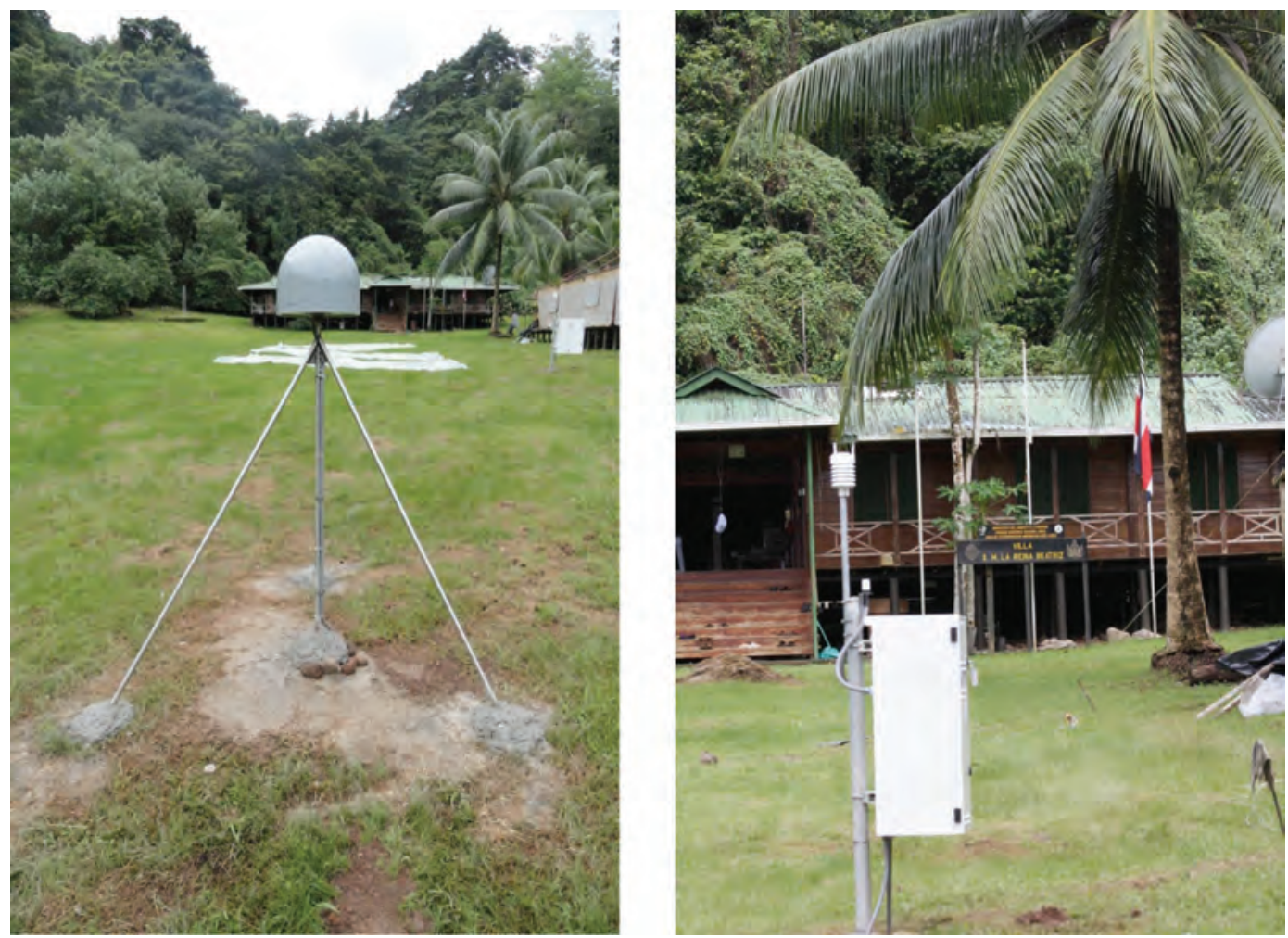

Fig. 3. ISCO CGPS monument at Wafer Bay (left). Box containing GPS receiver, met package, radio link and power supply (right).

long on $2.5 \mathrm{~cm}$ diameter solid stainless steel rod; one vertical and three inclined $35^{\circ}$ from the vertical and horizontally separated by $120^{\circ}$. A hand auger was used to dig, into fine sand, the four holes where the rods were cemented. The water table was only $2 \mathrm{~m}$ deep and therefore the possibility of monument subsidence over the first few months after installation was a concern. Liquefaction at the site from strong ground motion could also occur, but there are no records of large and close enough earthquakes around Isla del Coco that could generate high enough accelerations to trigger liquefaction.

The site is equipped with a Trimble choke ring antenna and a Trimble NetRS receiver. It is also equipped with a Vaisala WTX510/520 meteorological package that records temperature, humidity, atmospheric pressure, wind velocity and direction, and rain and hail precipitation by impact. The instruments are placed in an aluminum box located some $30 \mathrm{~m} \mathrm{SW}$ from the monument (Fig. 3). Data are transmitted via radio link from this box to a wireless router on Villa Beatriz and then served on the web via the VSAT link on the island. All data from this station, including met records, can be freely downloaded from the UNAVCO ftp site (ftp://data-out.unavco.org).

The location of the campaign site $\mathrm{COCO}$ and the CGPS station are shown in Figure 4 a. A site description for the monument COCO, including reference marks is given in Fig. $4 \mathrm{~b}$.

\section{RESULTS}

Campaign results: The GPS campaigns show that the average Isla del Coco motion in the ITRF2008 frame is $88.5 \pm 1.1 \mathrm{~mm} / \mathrm{yr}$ over the 17-year data span, and the station subsides at a rate of $1.6 \pm 1.6 \mathrm{~mm} / \mathrm{yr}$ (Table 1). Zero 


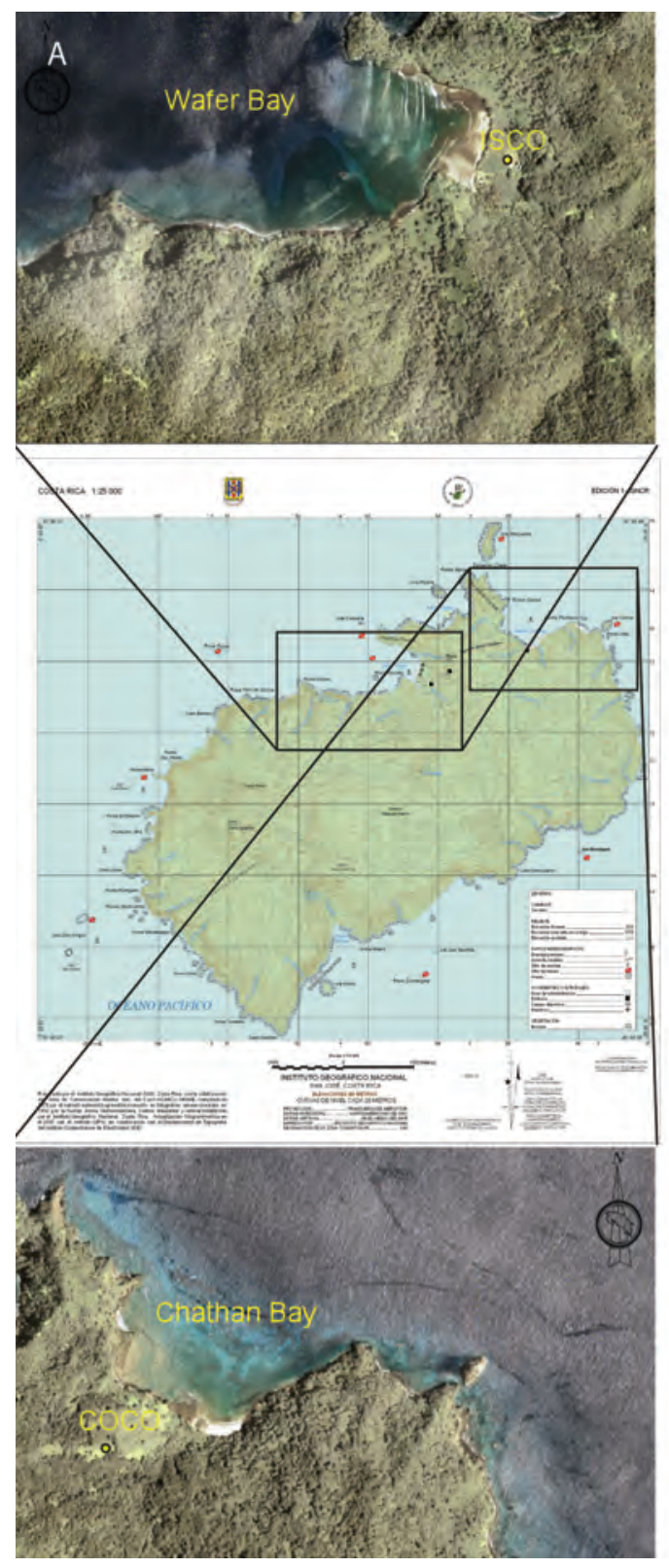

velocity in ITRF2008 is defined such that the motions all over the earth in ITRF2008 approximate a no-net-rotation of the lithosphere condition. This definition does not have any direct geological significance, but ITRF2008 is ideal for combining and comparing geodetic estimates, and the motions of most major plates in ITRF2008 are well known. However, motions of the Cocos and Caribbean plates are

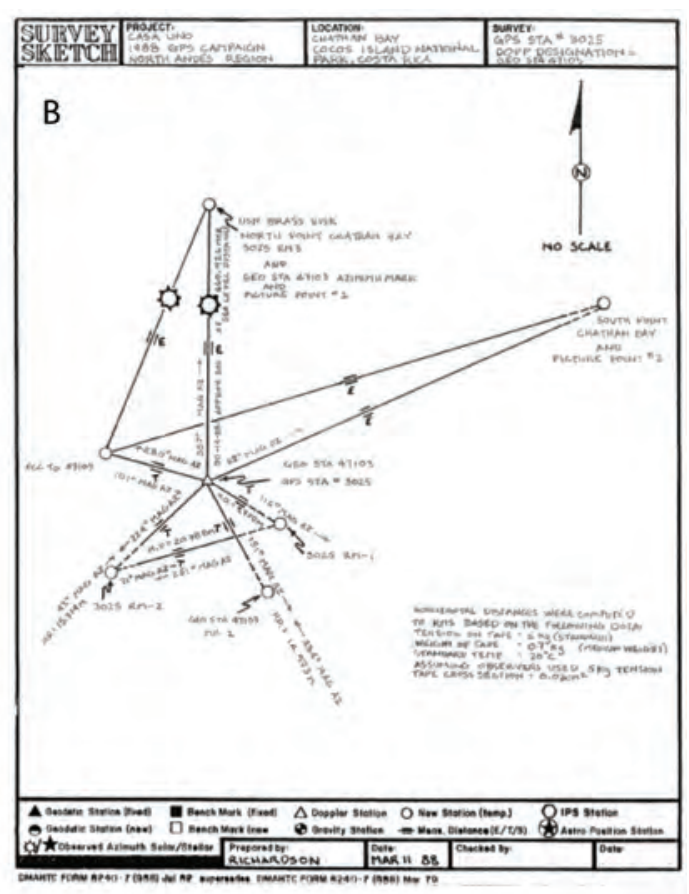

Fig. 4. (a) Map and aerial photographs showing location of sites ISCO and COCO. (b) site description for monument $\mathrm{COCO}$, including reference marks.

not constrained as well as other plates. After presenting the velocity for the new CGPS station ISCO, we will discuss the motion of Isla del Coco and the Cocos Plate relative to the Caribbean Plate.

It is interesting to compare the new results for the sites on Isla del Coco with the early studies of Dixon (1993) and Freymueller et al. (1993). These earlier studies reported only relative motions (changes of baselines), because no robust "absolute motion" frame like ITRF2008 existed at that time. The early studies estimated that the baseline between Isla del Coco and Liberia on the Costa Rica mainland shortened at a rate of $70 \pm 5 \mathrm{~mm} / \mathrm{yr}$ (Dixon 1993) or $71 \pm 4 \mathrm{~mm} / \mathrm{yr}$ (Freymueller et al. 1993), based on independent analyses of the same data. Using our 1991-2008 velocity for COCO and the 1991-1996 velocity for Liberia (LIBE), we estimate a more precise shortening rate of 
TABLE 1

Site velocities in ITRF2008 for sites used in this study. The table gives components of the 3D velocity vector in east, north and height, in $\mathrm{mm} / \mathrm{yr}$, along with the rate and azimuth of the horizontal velocity vector.

Azimuth is measured clockwise from north.

\begin{tabular}{lcccccccc}
\multicolumn{1}{c}{ Site } & Code & Latitude & Longitude & East & North & Height & Rate & Azimuth \\
Isla de Coco & COCO & 5.5476 & -87.0452 & $50.4 \pm 1.1$ & $72.8 \pm 0.6$ & $-1.6 \pm 1.6$ & $88.5 \pm 1.1$ & $35^{\circ}$ \\
Isla de Coco & ISCO & 5.5443 & -87.0558 & $51.7 \pm 1.9$ & $74.8 \pm 0.7$ & $-1.4 \pm 4.2$ & $90.9 \pm 2.0$ & $35^{\circ}$ \\
Liberia & LIBE & 10.6511 & -85.4249 & $9.0 \pm 1.5$ & $18.1 \pm 0.9$ & $-3.5 \pm 2.8$ & $20.2 \pm 1.5$ & $26^{\circ}$ \\
San Andrés & SAN0 & 12.5805 & -81.7157 & $12.0 \pm 0.1$ & $6.8 \pm 0.1$ & $0.2 \pm 0.2$ & $13.8 \pm 0.1$ & $60^{\circ}$ \\
\hline
\end{tabular}

$69 \pm 2 \mathrm{~mm} / \mathrm{yr}$, indicating that the early studies using 1988-1991 data had no significant biases.

\section{Isla del Coco movement based on ISCO:}

We processed continuous data from ISCO for the period May 20, 2011 to March 24, 2012. Data processing was done at the Geophysical Institute, University of Alaska at Fairbanks using the point positioning approach identical to that described above for the campaign data. A site on Isla San Andrés in the Caribbean (SAN0) is included among the many regional stations included in each daily solution.

Time series for the NS, EW and vertical components of motion at ISCO are shown in Figure 5. Motion is given relative to ITRF2008.
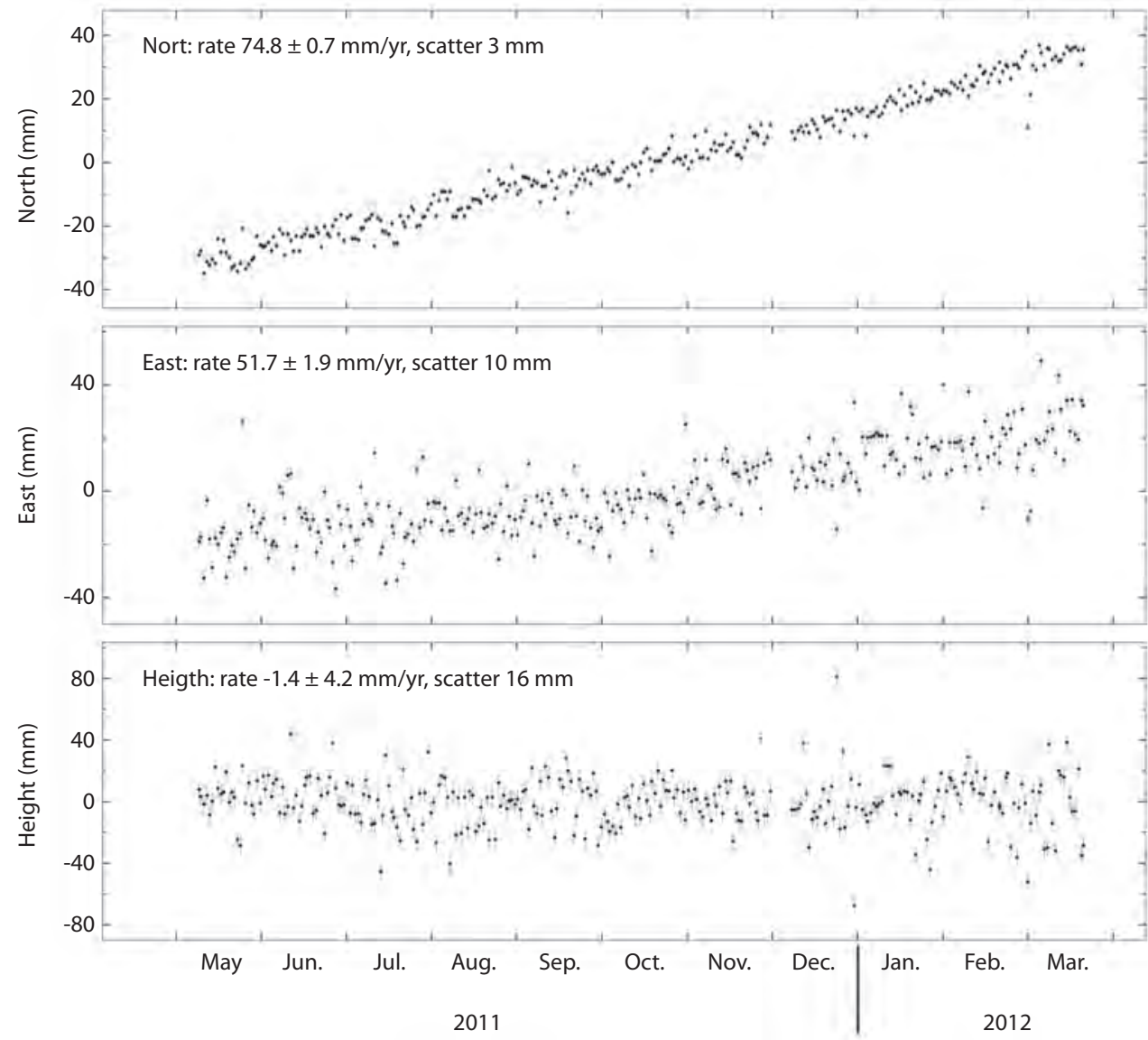

Fig. 5. Time series of ISCO motion in ITRF2008. 
The observed horizontal components of the velocity vector for ISCO result in a total speed of $90.9 \pm 1.5 \mathrm{~mm} / \mathrm{yr}$ in the $\mathrm{N} 35^{\circ} \mathrm{E}$ direction (Table 1). This estimate differs by only $2 \mathrm{~mm} /$ yr from the estimate based on the campaign data, which is within the estimated measurement uncertainties. ISCO subsides at a rate of $1 \pm 4 \mathrm{~mm} / \mathrm{yr}$. Given the very short CGPS time period, it is not surprising that the vertical rate is not significant relative to the uncertainty. The scatter of the daily solutions about the best-fit trend is $(10,3,16) \mathrm{mm}$ for the east, north and height components, respectively. The scatter in the data is quite large compared to most sites in North America and Europe, probably because of the large amount and variability of water vapor in the atmosphere in this tropical island environment.

Cocos-Caribbean convergence: We use the CGPS station running at Isla de San Andrés (SAN0), presumed to lie on the stable Caribbean Plate, and present here the first CGPS measurement of Cocos-Caribbean plate convergence (Fig. 6). The ISCO-SAN0 baseline is $\sim 973 \mathrm{~km}$ long and has a N36.5 ${ }^{\circ} \mathrm{E}$ orientation, almost parallel to Cocos Plate motion direction in ITR2008 and the orientation of

ISCO relative to SANO $(973 \mathrm{~km})$

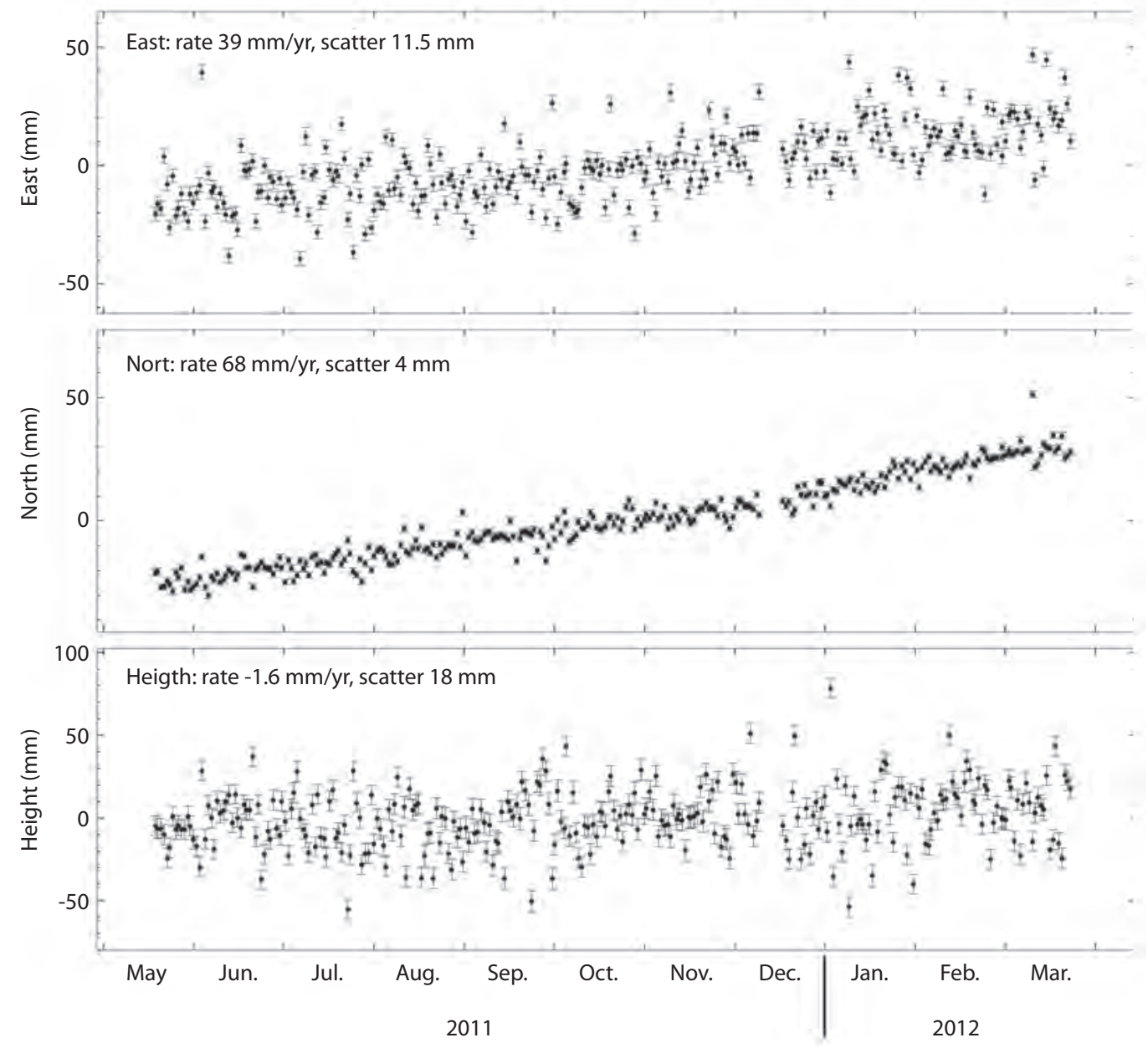

Fig. 6. Time series of contraction of the ISCO-SAN0 baseline. 
convergence off central Costa Rica where the baseline crosses the trench.

Our results show contraction of the baseline at $78 \pm 1 \mathrm{~mm} / \mathrm{yr}$, in agreement with the MORVEL estimate of $76.4 \pm 2.5 \mathrm{~mm} / \mathrm{yr}$ (DeMets et al. 2010; online calculator at http://www. geoscience.wisc.edu/ chuck/MORVEL). In contrast, the model of DeMets (2001) predicts $86.4 \mathrm{~mm} / \mathrm{yr}$ contraction for this baseline, and NUVEL-1A predicts $85.7 \mathrm{~mm} / \mathrm{yr}$ (DeMets et al., 1994). MORVEL represents an average of plate motions over the last 780,000 years, while the older models represent $\sim 3$ million year averages. Our result supports the conclusion of DeMets et al. (2010) that Cocos-Caribbean convergence has slowed over the last 3 million years, but suggests that Cocos-Caribbean convergence has occurred at a steady rate over the last 780,000 years.

Liberia moves relative to SAN0 at a rate of $11.7 \pm 1.5 \mathrm{~mm} / \mathrm{yr}$. The motion of Liberia relative to SAN0 results from a combination of motion of the Costa Rica forearc and elastic deformation resulting from the locked subduction plate interface (Lundgren et al. 1999; Iinuma et al., 2004; LaFemina et al., 2009). Dixon (1993) estimated a larger rate of almost $20 \mathrm{~mm} / \mathrm{yr}$. This difference might result from a measurement bias, but also could indicate temporal changes in the locked region. Transient slow slip events involving creep on part of the plate interface have been observed at the Nicoya Peninsula (Outerbridge et al., 2010), which means the rate elastic deformation observed in campaign data will depend on whether or not slow slip events occurred during the measurement interval. Our velocity for Liberia is consistent with the model prediction of Iinuma et al. (2004).

The precision of these CGPS plate motion vectors will improve considerably over the next few years, although the general trend will probably not change too much. With the addition this year of many more CGPS stations in and around the Caribbean Plate, as part of the COCONet initiative, we will have a better knowledge of the amount and concentration of internal deformation of the Caribbean Plate, and we will be able to distinguish between these two possibilities.

\section{CONCLUSIONS}

We obtained a velocity vector for the motion of Isla del Coco of $90.7 \pm 1.5 \mathrm{~mm} / \mathrm{yr}$ in the $\mathrm{N} 35^{\circ} \mathrm{E}$ direction, based on 10 months of data. This rate is equal within uncertainties to the rate estimated from two campaign surveys 17 years apart. A comparison of our results to the early studies of Dixon (1993) and Freymueller et al. (1993) shows the early studies suffered from no substantial biases as their results are consistent with ours at the level expected from the uncertainties, with the exception of the Liberia-San Andrés estimate of Dixon (1993). Assuming no internal deformation of Isla del Coco, the estimated velocity should be representative of the velocity of the Cocos Plate in ITRF2008. We also obtained contraction of the ISCO-SAN0 baseline at a rate of $78 \pm 1 \mathrm{~mm} /$ $\mathrm{yr}$, within $1.5 \mathrm{~mm} / \mathrm{yr}$ of the $76.4 \pm 2.5 \mathrm{~mm} / \mathrm{yr}$ convergence rate expected from the MORVEL model. This suggests that Cocos-Caribbean plate convergence has remained steady over the last 780,000 years, at a slower rate than predicted by the $\sim 3$ million year average of the NUVEL1A model.

The precision of the motion estimate from ISCO will become considerably more precise over the next few years, and the campaign estimate could also be improved substantially by adding the 1994 data (after measuring the offset between monuments and correcting for this offset), as the uncertainty is dominated by the 1991 survey. With the addition this year of many more CGPS stations in and around the Caribbean Plate, as part of the COCONet initiative, we will soon gain a much better knowledge of the amount and concentration of internal deformation of the Caribbean Plate, and the tectonic motions of the region.

\section{ACKNOWLEDGMENTS}

We would like to thank Fernando Cortés and Francisco González (r.i.p) for providing permits and logistical support to install the continuous GPS station in Isla del Coco. Park Rangers and other personnel from MINAET, 
Ministerio de Seguridad and Agua Viva Foundation, made the work in Isla del Coco a pleasant experience. The installation of ISCO is part of a joint initiative with the Escuela Centroamericana de Geología, at Universidad de Costa Rica, to instrument Isla del Coco. The air photographs shown in Fig. 4 were facilitated by the Alexander González Salas from the Programa de Regularización de Catastro y Registro de Costa Rica. The site SAN0 was established as part of the Caribbean Hurricane Prediction and Geodetic Network (PI John Braun of UCAR), and we appreciate the free and open availability of these data. We thank John Weber and two anonymous reviewers for reviews that helped us improve this manuscript.

\section{RESUMEN}

La Isla del Coco es la única porción emergida en la placa del Coco. Esta condición la hace el único lugar donde se puede medir, usando Sistemas de Navegación Global por Satélite (GNSS), la velocidad de dicha placa. Las mediciones con GPS en la Isla del Coco se han realizado por más de dos décadas, permitiendo obtener velocidades precisas. En mayo del 2001 se instaló una estación continua de GPS en la Isla del Coco como parte, tanto de la Red Regional de GNSS COCONet, como del Sistema de Monitoreo Geodinámico de Nicoya (SISMOGENICO). Resultados de esta estación continua muestran movimiento continuo de la Isla del Coco, con respecto a ITRF2008, a una velocidad de $90.9 \pm 1.5 \mathrm{~mm} /$ año con dirección $\mathrm{N} 35^{\circ} \mathrm{E}$ y convergencia con la placa del Caribe a $78 \pm 1 \mathrm{~mm} /$ año. Estas velocidades son consistentes con las obtenidas por MORVEL, un modelo geológico de velocidades de placas representativo de los últimos 780,000 años, y sugieren que la convergencia de estas placas se ha mantenido constante durante ese lapso de tiempo.

Palabras clave: Isla del Coco, Placa del Coco, Placa del Caribe, GPS continuo, velocidad de placas.

\section{REFERENCES}

Castillo, P., R. Batiza, D. Vanko, E. Malavassi, J. Barquero \& E. Fernández. 1988. Anomalously young volcanoes on old hot-spot traces. I. Geology and petrology of Cocos Island. Geol. Soc. Amer. Bull. 100: 1400-1414.

DeMets, C. 2001. A new estimate for present-day CocosCaribbean plate motion: Implications for slip along the Central American volcanic arc. Geophys. Res. Lett. 28: 4043-4046.

DeMets, C., R.G. Gordon, D.F. Argus \& S. Stein. 1994. Effect of recent revisions to the geomagnetic reversal time scale on estimates of current plate motions. Geophys. Res. Lett. 21: 2191-2194.

DeMets, C., R.G. Gordon \& D.F. Argus. 2010. Geologically current plate motions. Geophys. J. Int. 181: 1-80; doi:10.1111/j.1365-246X.2009.04491.x.

Dixon, T. 1993. GPS Measurement of relative motion of the Cocos and Caribbean plates and strain accumulation across the Middle America Trench. Geophys. Res. Lett. 20: 2167-2170.

Freymueller, J.T., J.N. Kellogg \& V. Vega. 1993. Plate motions in the North Andean Region. J. Geophys. Res. 98: 21,853-21,863.

Hey, R.N. 1977 Tectonic evolution of the Cocos-Nazca spreading center, Geol. Soc. Am. Bull., 88: 1404-1420.

Iinuma, T., M. Protti, K. Obana, V. González, R. Van der Laat, T. Kato, S. Miyazaki, Y. Kaneda \& E. Hernández. 2004. Inter-plate coupling in the Nicoya Peninsula, Costa Rica, as deduced from a transpeninsula GPS experiment. Earth Planet. Sci. Lett. 223: 203-212.

LaFemina, P., T.H. Dixon, R. Govers, E. Norabuena, H. Turner, A. Saballos, G. Mattioli, M. Protti \& W. Strauch. 2009. Fore-arc motion and Cocos Ridge collision in Central America. Geochem. Geophys. Geosyst. 10:Q05S14, doi:10.1029/2008GC002181.

Lonsdale, P.F. \& K.D. Klitgord 1978 Structure and tectonic history of the eastern Panama basin, Geol. Soc. Am. Bull. 89: 981-999.

Lundgren, P., M. Protti, A. Donnellan, M. Heflin, E. Hernandez \& D. Jefferson. 1999. Seismic cycle and plate margin deformation in Costa Rica: GPS observations from 1994 to 1997. J. Geophys. Res. 104: 28,915-28,926.

Outerbridge, K.C., T.H. Dixon, S.Y. Schwartz, J.I. Walter, M. Protti, V. Gonzalez, J. Biggs, M. Thorwart \& W. Rabbel. 2010. A tremor and slip event on the Cocos' Caribbean subduction zone as measured by a global positioning system (GPS) and seismic network on the Nicoya Peninsula, Costa Rica. J. Geophys. Res. 115: B10408, doi:10.1029/2009JB006845.

Wilson, D.S. 1996. Fastest known spreading on the Miocene Cocos-Pacific Plate Boundary. Geophys. Res. Lett. 23: 3003-3006.

Zumberge, J., M. Heflin, D. Jefferson, M. Watkins \& F. Webb. 1997. Precise point positioning for the efficient and robust analysis of GPS data from large networks. J. Geophys. Res. 102: 5005-5017. 
